\title{
BMJ Open Estimating population prevalence of potential airflow obstruction using different spirometric criteria: a pooled cross-sectional analysis of persons aged 40-95 years in England and Wales
}

\author{
Shaun Scholes, Alison Moody, Jennifer S Mindell
}

\section{To cite: Scholes S, Moody A, Mindell JS. Estimating population prevalence of potential airflow obstruction using different spirometric criteria: a pooled cross-sectional analysis of persons aged 40-95 years in England and Wales. BMJ Open 2014;4:e005685. doi:10.1136/bmjopen-2014- 005685 \\ ABSTRACT \\ Objectives: Consistent estimation of the burden of chronic obstructive pulmonary disease (COPD) has been hindered by differences in methods, including different spirometric cut-offs for impaired lung function. The impact of different definitions on the prevalence of potential airflow obstruction, and its associations with key risk factors, is evaluated using cross-sectional data from two nationally representative population surveys.}

\section{- Prepublication history and additional material is available. To view please visit the journal (http://dx.doi.org/ 10.1136/bmjopen-2014- 005685).}

Received 12 May 2014 Revised 7 July 2014 Accepted 8 July 2014

Design: Pooled cross-sectional analysis of Wave 2 of the UK Household Longitudinal Survey and the Health Survey for England 2010, including 7879 participants, aged 40-95 years, who lived in England and Wales, without diagnosed asthma and with good-quality spirometry data. Potential airflow obstruction was defined using self-reported physician-diagnosed COPD; a fixed threshold (FT) forced expiratory volume in $1 \mathrm{~s} /$ forced vital capacity $\left(\mathrm{FEV}_{1} / \mathrm{FVC}\right.$ ) ratio $<0.7$ and an age-specific, sex-specific, height-specific and ethnicspecific lower limit of normal (LLN). Standardised

\section{CrossMark}

Health and Social Surveys Research Group, Research Department of Epidemiology and Public Health, University College London, London, United Kingdom

Correspondence to Dr Shaun Scholes; s.scholes@ucl.ac.uk questions elicited self-reported information on demography, smoking history, ethnicity, occupation, respiratory symptoms and cardiovascular disease.

Results: Consistent across definitions, participants classed with obstructed airflow were more likely to be older, currently smoke, have higher pack-years of smoking and be engaged in routine occupations. The prevalence of airflow obstruction was $2.8 \%(95 \% \mathrm{Cl}$ $2.3 \%$ to $3.2 \%$ ), $22.2 \%$ (21.2\% to $23.2 \%$ ) and $13.1 \%$ (12.2\% to $13.9 \%$ ) according to diagnosed COPD, FT and LLN, respectively. The gap in prevalence between FT and LLN increased in older age groups. Sex differences in the risk of obstruction, after adjustment for key risk factors, was sensitive to the choice of spirometric cut-off, being significantly higher in men when using FT, compared with no significant difference using LLN.

Conclusions: Applying FT or LLN spirometric cut-offs gives a different picture of the size and distribution of the disease burden. Longitudinal studies examining differences in unscheduled hospital admissions and risk of death between FT and LLN may inform the choice as to the best way to include spirometry in assessments of airflow obstruction.

\section{Strengths and limitations of this study}

- Estimates of the burden of chronic obstructive pulmonary disease using spirometry data collected in epidemiological studies are inconsistent through differences in methods, including different spirometric cut-offs.

- Our study combined two nationally representative samples of adults living in England and Wales, with standardised protocols and objective measurements of lung function, and a wide range of clinically relevant conditions including selfreported respiratory symptoms (chronic cough and phlegm) and breathlessness.

- Consistent definitions and up-to-date reference equations were used, providing baseline data for monitoring purposes in the UK, and for facilitating comparison with international studies.

- Prevalence estimates were based on prebronchodilator lung function measurements, and so are likely to overestimate true prevalence.

\section{INTRODUCTION}

Chronic obstructive pulmonary disease (COPD) is characterised by a progressive decline in lung function. ${ }^{1}{ }^{2}$ In total, 2.9 million deaths were attributed to COPD in 2010, making it the third leading global cause of death. ${ }^{3}$ The National Outcomes Strategy for COPD estimated that 835000 people living in the UK are currently diagnosed with COPD, with a further 2.2 million being undiagnosed. ${ }^{4}$ COPD is the second leading cause of emergency hospital admission and is one of the most costly diseases in terms of acute hospital care in England. ${ }^{4}$

Healthcare budgeting is often contingent on the estimated burden of disease. Spirometry, the mainstay of lung function assessment, has been used in nationally representative surveys to estimate the COPD burden in terms of prevalence, associated 
comorbidities and mortality. Estimation of the disease burden has been hindered, however, by differences in methods, including spirometric cut-offs. ${ }^{5-8}$ Fixed thresholds (FTs) use cut-offs for lung function measurements (eg, forced expiratory volume in $1 \mathrm{~s} /$ forced vital capacity $\left(\mathrm{FEV}_{1} / \mathrm{FVC}\right)$ ratio $\left.<0.7\right)$ regardless of age, sex, height and ethnicity. ${ }^{9}$ An additional threshold for per cent-of-predicted $\mathrm{FEV}_{1}$ (expected for persons of a given age, sex, height and ethnicity) is also commonly used for severity classification. In contrast, a lower limit of normal (LLN) cut-off uses a statistical definition of abnormal/normal (eg, below/above the lower 5th centile of the distribution of age-specific, sex-specific, height-specific and ethnic-specific $\mathrm{FEV}_{1} / \mathrm{FVC}$ values from a healthy, lifelong non-smoking population). ${ }^{10}$

At present, applying FTs such as $\mathrm{FEV}_{1} / \mathrm{FVC}<0.7$ is the standard approach. However, the European Respiratory Society (ERS) Task Force on epidemiology recently advocated using the LLN in epidemiological studies as FTs overestimate airflow obstruction in older populations, due to the physiological reduction of $\mathrm{FEV}_{1} / \mathrm{FVC}$ with age, and underestimate in young adults, compared with LLN. ${ }^{11-16}$ The controversy over FT versus LLN thresholds is well known with no signs of a consensus among expert groups being agreed. ${ }^{17-21}$

Partly as a result of this controversy, the COPD epidemiological database shows heterogeneity in definitions and consequential estimates of the disease burden. ${ }^{5} 22$ Two nationally representative samples, Wave 2 (20102012) of the UK Household Longitudinal Survey (UKHLS, 'Understanding Society') and the Health Survey for England (HSE) 2010, collected lung function data using identical measurement protocols and specialist equipment, providing an opportunity to increase statistical precision by combining both data sets. Therefore, the primary objective of the present study was to compare the prevalence of 'potential' airflow obstruction according to FT and LLN thresholds among persons aged 40-95 years living in England and Wales: potential in the sense that the administration of bronchodilators to measure the extent of reversibility in airflow obstruction was not used. As a secondary aim, we compared the sensitivity of associations with risk factors including age, sex, smoking history and socioeconomic position. Using the same variables, we also examined the characteristics associated with spirometry in connection with self-reported physician-diagnosed COPD.

\section{METHODOLOGY}

\section{Study design and setting}

The UKHLS and HSE selected participants using stratified multistage probability sampling designs. ${ }^{23}$ Self-reported health information, risk factors and demographics were collected through face-to-face interviews, followed by a visit from a trained nurse during which lung function was measured. Response rates for the Wave 2 interview (among individuals issued) and nurse visit (among eligible participants in the Wave 2 interview) were $61 \%$ and $59 \%$, respectively, in UKHLS. In HSE 2010, interview (among the estimated total number of adults in sampled households) and nurse-visit (adults in co-operating households) response rates were $59 \%$ and $57 \%$. Sampling methods are described elsewhere. ${ }^{24-26}$ Eligible participants gave written consent to participate in spirometry.

\section{Questionnaire and procedures}

Participants were excluded from spirometry for the following safety reasons: pregnancy; had in the past 3 months abdominal/chest surgery, a heart attack, detached retina or eye or ear surgery; admitted to hospital with a heart complaint in the preceding month; a resting pulse rate $>120 \mathrm{bpm}$ or currently taking medications for the treatment of tuberculosis. Spirometry, without bronchodilator use, was conducted using NDD EasyOne PCC spirometers (NDD Medical Technologies, Zurich, Switzerland). Quality control was summarised in a session grade based on the number of technically acceptable blows and their reproducibility. Grades A (three acceptable manoeuvres, two highest FVC and $\mathrm{FEV}_{1}$ within $100 \mathrm{~mL}$ ), B (three acceptable manoeuvres, two highest $\mathrm{FVC}$ and $\mathrm{FEV}_{1}$ within $150 \mathrm{~mL}$ ) and $\mathrm{C}$ (two or three acceptable manoeuvres within $200 \mathrm{~mL}$ ) were considered good quality. Full details on measurement procedures are available elsewhere. ${ }^{25-27}$

The highest values for $\mathrm{FEV}_{1}$ and for $\mathrm{FVC}$, from at least three and up to eight blows, were used. Age-specific, sexspecific, height-specific and ethnic-specific predicted values and z-scores $\left(\mathrm{FEV}_{1}, \mathrm{FVC}\right.$ and $\left.\mathrm{FEV}_{1} / \mathrm{FVC}\right)$ were computed using the ERS Global Lungs Initiative (GLI 2012, http://www.lungfunction.org) reference equations. These have been prepared by an international collaboration based on data spanning 26 countries from $>70000$ healthy individuals across four ethnic groups (Caucasian, African-American, and North-East Asian and South-East Asian), valid for persons aged 3-95 years $^{28} 29$ and have been shown to fit contemporary Australasian spirometric data. ${ }^{30}$

\section{FT and LLN spirometric cut-offs}

Using FTs, we applied the 2007 Global Initiative for Chronic Obstructive Lung Disease (GOLD) classification, ${ }^{31}$ which was designed for use with postbronchodilator spirometry: potential airflow obstruction was defined as $\mathrm{FEV}_{1} / \mathrm{FVC}<0.7$ (FT). Disease stage was defined by the reduction in $\mathrm{FEV}_{1}$ relative to per cent-of-predicted values as follows: stage $\mathrm{I}\left(\mathrm{FEV}_{1} / \mathrm{FVC}<0.7\right.$ and $\mathrm{FEV}_{1}$ $\geq 80 \%$ of predicted); stage II $\left(\mathrm{FEV}_{1} / \mathrm{FVC}<0.7\right.$ and $\mathrm{FEV}_{1}$ $50-79 \%$ of predicted) and stage III $+\left(\mathrm{FEV}_{1} / \mathrm{FVC}<0.7\right.$ and $\mathrm{FEV}_{1}<50 \%$ of predicted). ${ }^{32}$ Participants with $\mathrm{FEV}_{1} / \mathrm{FVC} \geq 0.7$ were defined as non-obstructed.

Participants with $\mathrm{FEV}_{1} / \mathrm{FVC}<\mathrm{LLN}$ (below the lower 5 th centile of the distribution of $\mathrm{z}$-scores) were defined as obstructed (LLN). To examine possible heterogeneity among participants with $\mathrm{FEV}_{1} / \mathrm{FVC}<\mathrm{LLN}$, disease stage 
was defined by $\mathrm{FEV}_{1}$ relative to LLN as follows: stage I $\left(\mathrm{FEV}_{1} / \mathrm{FVC}<\mathrm{LLN}\right.$ and $\left.\mathrm{FEV}_{1} \geq \mathrm{LLN}\right)$ and stage II $\left(\mathrm{FEV}_{1} / \mathrm{FVC}<\mathrm{LLN}\right.$ and $\left.\mathrm{FEV}_{1}<\mathrm{LLN}\right) .{ }^{33}$ Participants with $\mathrm{FEV}_{1} / \mathrm{FVC} \geq \mathrm{LLN}$ were defined as non-obstructed. The fifth centile was chosen due to its established associations with respiratory symptoms and all-cause mortality. ${ }^{34}$

\section{Physician-diagnosed COPD}

In UKHLS, disease status was ascertained through questions asking "Has a doctor or other health professional ever told you that you have [disease]?" Diagnosed COPD was defined as a positive response to either chronic bronchitis or emphysema. In HSE, diagnosed COPD was defined as a positive response to the question "Did a doctor ever tell you that you had chronic bronchitis, emphysema or COPD?"

\section{Risk factors, measurements of lung function and comorbidities}

Key subgroups were defined by age $(40-54,55-64$, 65-74, 75-95); sex; smoking status (current, former, never); pack-years of cigarette smoking (a cumulative total reflecting the amount and duration of consumption, with 1 pack-year equating to an average of 20 cigarettes smoked/day for 1 year) and socioeconomic position, defined by the National Statistics SocioEconomic Classification (NS-SEC), grouped into professional, intermediate and routine occupations.

$\mathrm{FEV}_{1}, \mathrm{FVC}$ and $\mathrm{FEV}_{1} / \mathrm{FVC}$, on a continuous scale, were expressed as per cent-of-predicted values. Additional variables included current use of respiratory medicine; area of residence (urban/rural); body mass index (weight in kilograms divided by the square of height in metres), grouped into normal weight (18.5$\left.24.9 \mathrm{~kg} / \mathrm{m}^{2}\right)$, overweight $\left(25-29.9 \mathrm{~kg} / \mathrm{m}^{2}\right)$ and obese $\left(\geq 30 \mathrm{~kg} / \mathrm{m}^{2}\right)$; diagnosed diabetes; poor self-rated health and reported cardiovascular disease (stroke, angina, myocardial infarction). In HSE, participants were asked to name any long-standing illness: respiratory diseases were identified using International Classification of Diseases, Tenth Revision codes J00-J99. In the HSE, presence of respiratory symptoms was defined as usually coughing first thing in the morning, for at least 3 months/year, and bringing up phlegm from the chest most days for three consecutive months in a year. In the HSE, participants with some limitation of activity due to breathlessness during daily living were identified by a score of 3+ on the Medical Research Council (MRC) dyspnoea scale. Exposure to passive smoking in the HSE was measured by reported number of hours/week currently exposed to cigarette smoke $(0,1-9$ and $\geq 10 \mathrm{~h})$.

\section{Statistical analyses}

A lower age limit was used of 40 years due to the low prevalence of non-asthma airflow obstruction in the youngest age groups. ${ }^{35}$ As bronchodilators were not used, we excluded participants who reported diagnosed asthma. $^{34}$ 36-38 Five sets of analyses were conducted across the categories of diagnosed COPD, FT and LLN. First, participants' characteristics (demographics, risk factors, comorbidities and per cent-of-predicted $\mathrm{FEV}_{1}$, FVC and $\mathrm{FEV}_{1} / \mathrm{FVC}$ ) were summarised as means, accompanied by $\mathrm{SD}$, or as counts accompanied by percentages. Participants were counted under each relevant definition. Participants with/without obstruction were compared using the $\chi^{2}$ test and analysis of variance for categorical and continuous variables, respectively. ${ }^{39}$

Second, prevalence estimates were computed for a subset of sociodemographic variables defined by age, sex, smoking status, pack-years of cigarette smoking and NS-SEC. Third, in the absence of a gold standard, we calculated the sensitivity and specificity of each spirometric criterion, using the alternative cut-off as the reference standard. ${ }^{40}$

Fourth, regression analyses were performed using age, sex, pack-years of smoking and NS-SEC as independent variables with airflow obstruction as outcome. Current smoking status could not be entered in the same model as pack-years due to significant collinearity. The dependent variable based on FTs had four categories: nonobstructed, stage I, stage II and stage III+. The LLN-derived outcome had three categories: nonobstructed, stage I and stage II. In each case, multinomial logistic regression was used to estimate relative risk ratios (RRRs), with non-obstructed as the reference category. Multinomial logistic regression generalises logistic regression to outcomes with more than two possible discrete outcomes. The RRR is interpreted as the relative risk of one outcome in relation to the reference category for a specified category of an independent variable compared with the reference. ${ }^{41}{ }^{42}$ Diagnosed COPD was analysed as a binary outcome (not reported/ reported): logistic regression was therefore used to estimate ORs. ${ }^{39} 41$ The overall association for independent variables with $>2$ categories was computed using the adjusted Wald test. The likelihood ratio test was used to estimate the statistical significance of interaction terms: non-significant terms were excluded, and models refitted with only the main effects.

Fifth, to examine risk factors associated with possible underdiagnosis, a four-category outcome variable was created combining diagnosed COPD and spirometric criteria as follows: (1) neither diagnosed nor spirometrically defined obstruction; (2) physician-diagnosed COPD but no obstructive spirometry; (3) spirometrically defined but no diagnosed COPD and (4) both diagnosed and obstructive spirometry. ${ }^{43}$ FT and LLN cut-offs were analysed separately. RRRs generated from multinomial logistic regressions were used to examine associations between the same set of risk factors listed above and the composite dependent variable.

Participants with missing values on covariates were excluded from relevant analyses. Tests of statistical significance were based on two-sided probability $(p<0.05)$. Data set preparation was performed in SPSS V.20.0 (SPSS IBM Inc, Chicago, Illinois, USA), Stata V.13.1 
(StataCorp, College Station, Texas, USA) and R (V.3.0.3; $\mathrm{R}$ Foundation, http://www.r-project.org). Analysis was conducted in Stata accounting for the complex design of both surveys, using the appropriate weighting variables and primary sampling units. Both datasets are available via the UK Data Service (http://www. ukdataservice.ac.uk).

\section{Sensitivity analyses}

Analyses were initially undertaken excluding participants with reported diagnosed asthma and then repeated including those with asthma. In accordance with the previous UK National Institute for Health and Care Excellence (NICE) recommendations, ${ }^{44}$ comparisons between FT and LLN were rerun defining only the subset of FT participants with $\mathrm{FEV}_{1}<80 \%$ of predicted (ie, stage II+) as having obstructed airflow.

\section{RESULTS}

The analytical sample comprised 7879 participants (5936 and 1943 from UKHLS and HSE, respectively) aged 40-95 years, who resided in England and Wales, did not report diagnosed asthma, had valid values of height and ethnicity and provided good-quality spirometry. Response flow charts for the UKHLS and HSE are provided in online supplementary figures S1 and S2, respectively. Excluded participants were more likely to be older, engaged in routine occupations and selfreported respiratory symptoms (data not shown). Differences between the UKHLS and HSE in terms of sex ratio, age, smoking history, NS-SEC and objective measurements of lung function were not materially important (see online supplementary table S1).

Descriptive characteristics of the analytical sample according to physician-diagnosed COPD, FT and LLN are shown in online supplementary tables S2 and S3. Overall, $46.8 \%$ of participants were men, with mean age 57.6 years (SD 12.3), $16.6 \%$ were current smokers, $4.6 \%$ had $>50$ pack-years of cigarette smoking and $36.5 \%$ were engaged in professional occupations. Twelve $(0.1 \%)$ and $265(3.2 \%)$ participants had missing values for pack-years and NS-SEC, respectively. The prevalence of diagnosed COPD was similar between the sexes $(\mathrm{p}=0.349)$, but was higher for men using FT and LLN (both $\mathrm{p}<0.001$ ). Participants with diagnosed COPD/obstructive spirometry were more likely to be older, currently smoke, have higher pack-years of smoking and be engaged in routine occupations (all $\mathrm{p}<0.001$ ). Prevalence of diagnosed COPD was higher in HSE versus UKHLS $(p<0.001)$, but survey-specific prevalence was similar for FT and for LLN. Participants with diagnosed COPD/obstructive spirometry were more likely to report respiratory symptoms (chronic cough and phlegm) and disease, current use of respiratory medications, cardiovascular disease, breathlessness, poor self-rated health and have, on average, lower (per cent-of-predicted) values of $\mathrm{FEV}_{1}, \mathrm{FVC}$ and $\mathrm{FEV}_{1} / \mathrm{FVC}$. The prevalence of respiratory symptoms was
$13.7 \%, 10.2 \%$ and $11.3 \%$ among participants classed as having airflow obstruction according to diagnosed COPD, FT and LLN, respectively; prevalence of having a score of 3+ on the MRC dyspnoea scale was $34.8 \%, 12.3 \%$ and $15.9 \%$.

\section{Prevalence of airflow obstruction}

The prevalence of airflow obstruction was $2.8 \%, 22.2 \%$ and $13.1 \%$ using diagnosed COPD, FT and LLN, respectively (table 1). Using FTs, $11.6 \%, 8.9 \%$ and $1.7 \%$ of participants were classed as stage I, stage II and stage III+, respectively. LLN-derived obstruction was $6.6 \%$ (stage I) and $6.4 \%$ (stage II). For most subgroups, prevalence was highest for FT and lowest for diagnosed COPD, with LLN falling in between. The gap in prevalence between FT and LLN increased in older age groups. Prevalence among participants aged 40-54 years was $11.9 \%$ and $10.7 \%$ using FT and LLN, respectively. Prevalence among participants aged $75-95$ was $45 \%$ and $17.2 \%$.

Table 2 shows estimates of sensitivity and specificity for FT and LLN, using the alternative spirometric cut-off as the reference standard. When using LLN as reference, specificity-the percentage of participants classed as non-obstructed using LLN identified as non-obstructed using FT-decreased from $94.9 \%$ among participants aged $40-64$ years to $74.4 \%$ among those aged $65-95$.

\section{Multivariate analyses of airflow obstruction}

Table 3 shows the significant risk factors for diagnosed COPD, and the FT and LLN disease stage classifications (non-obstructed as reference category). For diagnosed COPD, the significant interaction between sex and age group $(\mathrm{p}=0.022)$ suggested no difference in odds between the sexes among participants aged 40-64 years, but higher odds among men aged 65-95. Using FTs, being male was associated with a significantly increased risk of airflow obstruction: RRR 1.35 (95\% CI 1.16 to 1.58), RRR 1.35 (1.12 to 1.63 ) and RRR 1.72 (1.08 to 2.76) for stages I, II and III+, respectively. In contrast, sex differences were not significant using LLN: RRR 1.07 (0.88 to 1.31 ) for stage I and RRR 1.20 (0.96 to 1.50) for stage II.

Odds of diagnosed COPD increased significantly with age only in men $(p=0.022$ for the interaction term). Using non-obstruction as reference, RRRs increased significantly with age when using FTs $(p<0.001$ for each stage). The age-related difference using LLN was more marked for stage II $(p=0.492$ and $p<0.001$ for stages I and II, respectively). A dose-related increased risk with pack-years of cigarette smoking was observed across each definition $(p<0.001)$. The difference between NS-SEC levels was more marked with diagnosed COPD ( $p=0.012)$ and the tightest FT and LLN definitions (FT: $\mathrm{p}=0.002$ stage III+; LLN: $\mathrm{p}<0.001$ stage II).

\section{Combination of diagnosed COPD and spirometric cut-offs}

The significant risk factors for the two four-category outcome variables created as a composite of diagnosed 


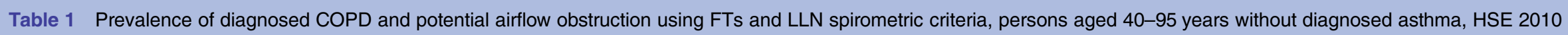
and UKHLS Wave 2 (2010-2012)*

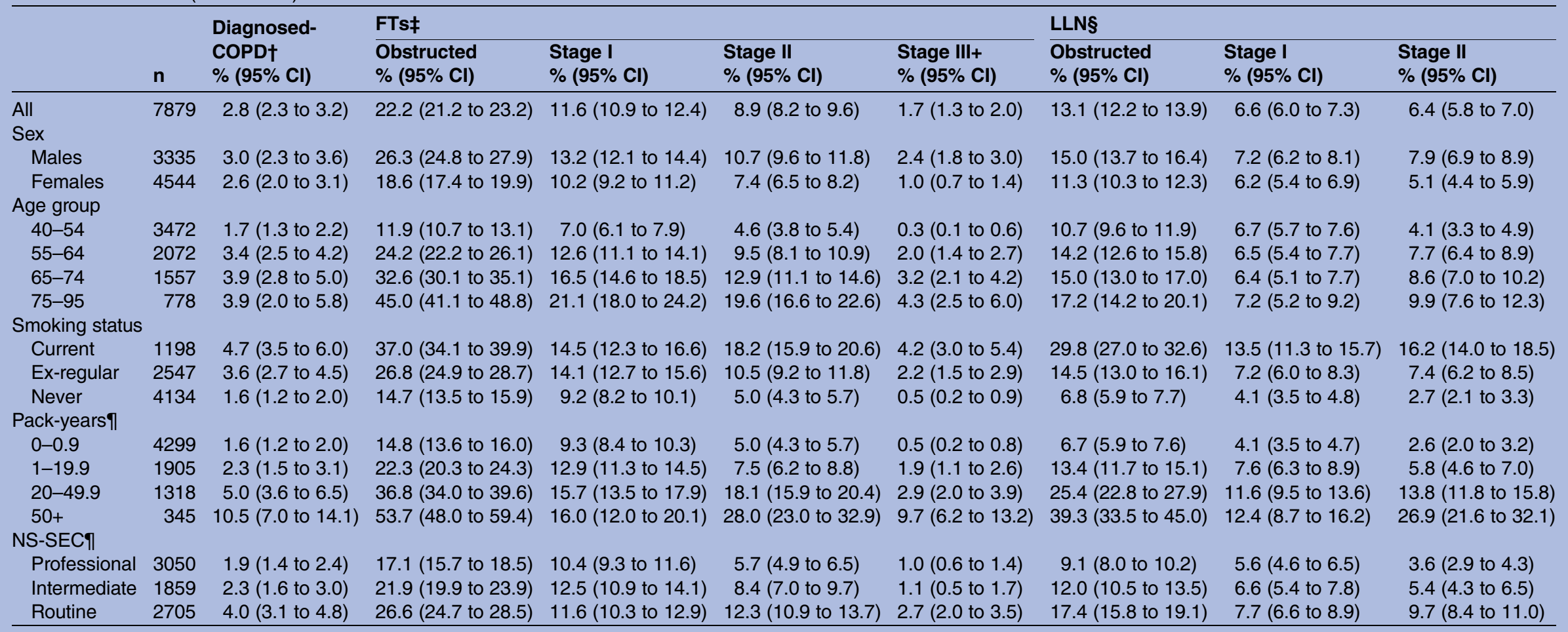

${ }^{*}$ Participants were included under each relevant definition. Bronchodilators were not used. Cell counts are unweighted; prevalence estimates were weighted.

†HSE: reported diagnosed COPD, bronchitis or emphysema; UKHLS: diagnosed bronchitis or emphysema.

fFTs: obstruction (FT): $\mathrm{FEV}_{1} / \mathrm{FVC}<0.7$. Staging classification: stage I $\left(\mathrm{FEV}_{1} / \mathrm{FVC}<0.7\right.$ and $\mathrm{FEV}_{1} \geq 80 \%$ of predicted); stage II (FEV $/ \mathrm{FVC}<0.7$ and $\mathrm{FEV}{ }_{1} 50-79 \%$ of predicted); stage III-

( $F E V_{1} / F V C<0.7$ and $\mathrm{FEV}_{1}<50 \%$ of predicted).

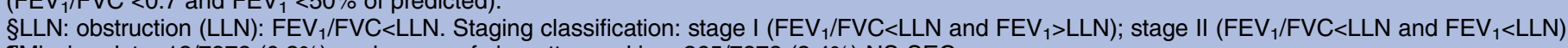

TMissing data: $12 / 7879(0.2 \%)$ pack-years of cigarette smoking; $265 / 7879(3.4 \%)$ NS-SEC.

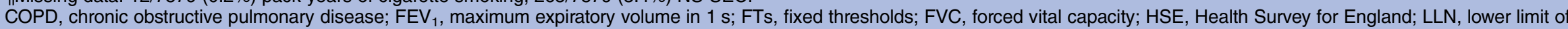
normal (below the lower 5th centile of z-scores); NS-SEC, National Statistics Socio-Economic Classification; UKHLS, UK Household Longitudinal Survey. 
Table 2 Sensitivity and specificity of FTs and LLN spirometric criteria by age group, persons aged $40-95$ years without diagnosed asthma, Health Survey for England 2010 and UK Household Longitudinal Survey Wave 2 (2010-2012)

\begin{tabular}{|c|c|c|c|c|}
\hline & $40-64(n=5544)$ & $65-95(n=2335)$ & $40-64(n=5544)$ & $65-95(n=2335)$ \\
\hline & \multicolumn{2}{|c|}{ FT using LLN as reference standard } & \multicolumn{2}{|c|}{ LLN using FT as reference standard } \\
\hline False positives (\%) & 5.1 & 25.6 & 0.4 & 0.0 \\
\hline False negatives (\%) & 2.5 & 0.0 & 28.0 & 57.6 \\
\hline Sensitivity & 0.975 & 1.000 & 0.720 & 0.424 \\
\hline Specificity & 0.949 & 0.744 & 0.996 & 1.000 \\
\hline PPV & 0.720 & 0.424 & 0.975 & 1.000 \\
\hline NPV & 0.996 & 1.000 & 0.949 & 0.744 \\
\hline$\kappa$ coefficient & 0.801 & 0.479 & 0.801 & 0.479 \\
\hline Likelihood ratio positive & 18.98 & 3.90 & 200.65 & N/A \\
\hline \multirow[t]{2}{*}{ Likelihood ratio negative } & 0.027 & 0.000 & 0.281 & 0.576 \\
\hline & \multicolumn{2}{|c|}{$\begin{array}{l}\text { FT (stage II+) using LLN as reference } \\
\text { standard }\end{array}$} & \multicolumn{2}{|c|}{$\begin{array}{l}\text { LLN using FT (stage II+) as reference } \\
\text { standard }\end{array}$} \\
\hline False positives (\%) & 1.3 & 8.9 & 6.3 & 5.2 \\
\hline False negatives (\%) & 49.2 & 26.7 & 16.0 & 39.1 \\
\hline Sensitivity & 0.508 & 0.733 & 0.840 & 0.609 \\
\hline Specificity & 0.987 & 0.911 & 0.937 & 0.948 \\
\hline PPV & 0.840 & 0.609 & 0.508 & 0.733 \\
\hline NPV & 0.937 & 0.948 & 0.987 & 0.911 \\
\hline$\kappa$ coefficient & 0.597 & 0.596 & 0.597 & 0.596 \\
\hline Likelihood ratio positive & 38.82 & 8.28 & 13.27 & 11.67 \\
\hline Likelihood ratio negative & 0.499 & 0.292 & 0.170 & 0.412 \\
\hline
\end{tabular}

COPD and obstructive spirometry are shown in table 4. Relative to the reference category (neither doctordiagnosed nor spirometrically defined airflow obstruction), the risk of reporting COPD in the absence of obstructive spirometry was significantly lower in men using either spirometric criterion (FT: RRR $0.53(95 \%$ CI 0.32 to 0.87 ); LLN: RRR 0.56 (0.35 to 0.89$)$ ). The risk of having obstructed airflow using spirometry but with no diagnosed COPD-thereby indicating possible underdiagnosis-was significantly higher in men, and in older age groups, when using FT but not LLN. For both spirometric criterions, increases in risk with increasing pack-years of cigarette smoking, relative to the reference, was consistent across combinations of COPD/obstructive spirometry; the difference between NS-SEC levels was more marked for obstructive spirometry.

\section{Sensitivity analyses}

Repeating analyses by including 1183 participants with reported diagnosed asthma increased prevalence of diagnosed COPD, FT and LLN by 2-3 percentage points (see online supplementary figure S3), but showed similar patterns of association with risk factors. Diagnosed asthma was a strong predictor of diagnosed COPD and obstructive spirometry $(p<0.001$, data not shown). Narrowing FT-defined obstruction to the subset of FT participants with $\mathrm{FEV}_{1}<80 \%$ of predicted (ie, stage II + ) more than halved the FT-derived prevalence $(22.2 \%$ vs $10.6 \%)$. Among participants aged $65-95$ years, specificity using LLN as the reference standard was
$74.4 \%$ and $91.1 \%$ for FT and FT stage II+, respectively (table 2). Patterns of association with risk factors using FT stage II+ were similar to those shown for FT.

\section{DISCUSSION}

Consistent estimation of the COPD burden has been hindered by differences in methods, including disagreement among experts over the choice of FT versus LLN spirometric cut-offs. ${ }^{5-8}$ In this study, we combined two nationally representative surveys, with standardised protocols and objective lung function measurements, to evaluate the impact of different definitions on the prevalence of potential airflow obstruction, and its associations with key risk factors. Participants with diagnosed COPD/obstructive spirometry were more likely to be older, currently smoke, have higher pack-years of cigarette smoking, be in lower socioeconomic groups and report the presence of respiratory symptoms (chronic cough and phlegm), cardiovascular disease, breathlessness and poor self-rated health. Among persons aged 40-95 years without physician-diagnosed asthma, prevalence was $2.8 \%, 22.2 \%$ and $13.1 \%$, according to diagnosed COPD, FT and LLN, respectively. The gap in prevalence between FT and LLN increased in older age groups. When using LLN as the reference standard, specificity for FT decreased from $94.9 \%$ among participants aged $40-64$ years to $74.4 \%$ among participants aged $65-$ 95 , corresponding to false-positive rates of $5.1 \%$ and $25.6 \%$, respectively. Sex differences in the risk of 


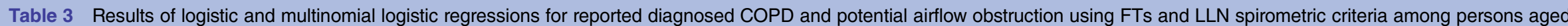
40-95 years, HSE 2010 and UKHLS Wave 2 (2010-2012)*

\begin{tabular}{|c|c|c|c|c|c|c|c|}
\hline \multirow[b]{3}{*}{ Characteristics } & \multirow[b]{3}{*}{$\mathbf{N}$} & \multirow[b]{3}{*}{$\begin{array}{l}\text { Diagnosed-COPD† } \\
\text { OR }(95 \% \mathrm{Cl})\end{array}$} & \multicolumn{3}{|l|}{ FTsł } & \multicolumn{2}{|l|}{ LLN§ } \\
\hline & & & \multicolumn{3}{|c|}{ Non-obstructed as reference } & \multicolumn{2}{|c|}{ Non-obstructed as reference } \\
\hline & & & $\begin{array}{l}\text { Stage I } \\
\text { RRR }(95 \% \mathrm{Cl}) \emptyset\end{array}$ & $\begin{array}{l}\text { Stage II } \\
\text { RRR }(95 \% \mathrm{Cl}) \rrbracket\end{array}$ & $\begin{array}{l}\text { Stage III+ } \\
\text { RRR }(95 \% \mathrm{Cl}) \rrbracket\end{array}$ & $\begin{array}{l}\text { Stage I } \\
\text { RRR }(95 \% \mathrm{Cl}) \uparrow\end{array}$ & $\begin{array}{l}\text { Stage II } \\
\text { RRR }(95 \% \mathrm{Cl}) \text { П }\end{array}$ \\
\hline \multicolumn{8}{|l|}{ Sex } \\
\hline Females** & 4372 & 1.00 & 1.00 & 1.00 & 1.00 & 1.00 & 1.00 \\
\hline Males & 3231 & $0.60(0.34$ to 1.05$)$ & 1.35 (1.16 to 1.58$)$ & 1.35 (1.12 to 1.63$)$ & 1.72 (1.08 to 2.76$)$ & 1.07 (0.88 to 1.31$)$ & $1.20(0.96$ to 1.50$)$ \\
\hline$p$ Value & & 0.075 & $<0.001$ & 0.002 & 0.024 & 0.503 & 0.107 \\
\hline \multicolumn{8}{|l|}{ Age group } \\
\hline $40-54^{\star \star}$ & 3416 & 1.00 & 1.00 & 1.00 & 1.00 & 1.00 & 1.00 \\
\hline $55-64$ & 2022 & 1.66 (1.07 to 2.58$)$ & 2.00 (1.63 to 2.45$)$ & 2.13 (1.65 to 2.73$)$ & 6.05 (2.82 to 12.99$)$ & $0.92(0.72$ to 1.18$)$ & 1.57 (1.20 to 2.06$)$ \\
\hline $65-74$ & 1451 & $0.96(0.54$ to 1.70$)$ & 2.85 (2.30 to 3.53 ) & 3.01 (2.32 to 3.89 ) & 10.11 (4.55 to 22.49 ) & 0.83 (0.63 to 1.09$)$ & 1.56 (1.16 to 2.12$)$ \\
\hline $75+$ & 714 & $1.20(0.39$ to 3.70$)$ & 4.72 (3.66 to 6.07$)$ & 6.67 (5.00 to 8.90$)$ & 22.26 (9.45 to 52.44$)$ & $1.06(0.74$ to 1.51$)$ & $2.20(1.52$ to 3.17$)$ \\
\hline$p$ Value & & 0.104 & $<0.001$ & $<0.001$ & $<0.001$ & 0.492 & $<0.001$ \\
\hline \multicolumn{8}{|l|}{ Pack-yearst† } \\
\hline $0-0.9^{\star \star}$ & 4165 & 1.00 & 1.00 & 1.00 & 1.00 & 1.00 & 1.00 \\
\hline $1-19.9$ & 1835 & 1.38 (0.88 to 2.17$)$ & 1.61 (1.34 to 1.93$)$ & 1.66 (1.29 to 2.15$)$ & $3.82(1.80$ to 8.14$)$ & 1.94 (1.51 to 2.49$)$ & 2.22 (1.58 to 3.12 ) \\
\hline 20-49.9 & 1269 & 2.91 (1.91 to 4.45$)$ & 2.30 (1.86 to 2.85$)$ & 4.56 (3.64 to 5.72 ) & 5.91 (2.81 to 12.45$)$ & 3.39 (2.61 to 4.41$)$ & 5.43 (3.98 to 7.41$)$ \\
\hline $50+$ & 334 & 5.64 (3.45 to 9.22$)$ & 2.34 (1.63 to 3.35$)$ & 6.83 (4.85 to 9.63 ) & 17.27 (7.88 to 37.84$)$ & 4.50 (2.96 to 6.84$)$ & 11.20 (7.59 to 16.52$)$ \\
\hline$p$ Value & & $<0.001$ & $<0.001$ & $<0.001$ & $<0.001$ & $<0.001$ & $<0.001$ \\
\hline \multicolumn{8}{|l|}{ NS-SEC†† } \\
\hline Professional** & 3047 & 1.00 & 1.00 & 1.00 & 1.00 & 1.00 & 1.00 \\
\hline Intermediate & 1855 & $1.03(0.68$ to 1.58$)$ & 1.18 (0.97 to 1.45$)$ & 1.34 (1.04 to 1.72$)$ & 1.01 (0.51 to 2.00$)$ & 1.14 (0.88 to 1.48$)$ & 1.35 (0.99 to 1.85$)$ \\
\hline Routine & 2701 & $1.61(1.13$ to 2.31$)$ & 1.07 (0.89 to 1.29$)$ & 1.82 (1.47 to 2.26$)$ & 2.30 (1.36 to 3.88$)$ & 1.28 (1.01 to 1.63$)$ & 2.18 (1.67 to 2.85$)$ \\
\hline $\mathrm{p}$ Value & & 0.012 & 0.246 & $<0.001$ & 0.002 & 0.123 & $<0.001$ \\
\hline \multicolumn{8}{|l|}{ Sample } \\
\hline UKHLS $^{* *}$ & 5675 & 1.00 & 1.00 & 1.00 & 1.00 & 1.00 & 1.00 \\
\hline HSE & 1928 & $2.22(1.60$ to 3.07$)$ & 0.95 (0.79 to 1.14$)$ & 0.97 (0.79 to 1.20$)$ & 0.99 (0.62 to 1.59$)$ & 1.05 (0.82 to 1.33$)$ & 0.99 (0.77 to 1.26$)$ \\
\hline $\mathrm{p}$ Value & & $<0.001$ & 0.587 & 0.798 & 0.967 & 0.716 & 0.913 \\
\hline \multicolumn{8}{|l|}{ Malesxage group } \\
\hline $40-549$ & 1319 & 1.00 & - & - & - & - & - \\
\hline $55-64$ & 876 & $1.16(0.54$ to 2.45$)$ & - & - & - & - & - \\
\hline $65-74$ & 664 & 3.21 (1.40 to 7.39$)$ & - & - & - & - & - \\
\hline $75+$ & 372 & 2.61 (0.67 to 10.22$)$ & - & - & - & - & - \\
\hline$p$ Value & & 0.022 & - & - & - & - & - \\
\hline
\end{tabular}


Table 4 Results of multinomial logistic regressions for combined outcome variable based on diagnosed COPD and potential airflow obstruction using FTs and LLN spirometric criteria among persons aged 40-95 years, HSE 2010 and UKHLS Wave 2 (2010-2012)*

\begin{tabular}{|c|c|c|c|c|c|c|c|}
\hline \multirow[b]{3}{*}{ Characteristics } & \multirow[b]{3}{*}{$\mathbf{n}$} & \multicolumn{3}{|l|}{ FTs } & \multicolumn{3}{|l|}{ LLN‡ } \\
\hline & & \multicolumn{3}{|c|}{ Neither diagnosed nor obstructive spirometry as reference } & \multicolumn{3}{|c|}{ Neither diagnosed nor obstructive spirometry as reference } \\
\hline & & $\begin{array}{l}\text { Diagnosed alone } \\
\text { RRR }(95 \% \mathrm{Cl}) \S\end{array}$ & $\begin{array}{l}\text { Obstructive } \\
\text { spirometry alone } \\
\text { RRR }(95 \% \mathrm{Cl}) \S \\
\end{array}$ & $\begin{array}{l}\text { Diagnosed and } \\
\text { obstructive spirometry } \\
\text { RRR }(95 \% \mathrm{Cl}) \S\end{array}$ & $\begin{array}{l}\text { Diagnosed alone } \\
\text { RRR }(95 \% \mathrm{CI}) \S\end{array}$ & $\begin{array}{l}\text { Obstructive } \\
\text { spirometry alone } \\
\text { RRR }(95 \% \mathrm{Cl}) \S \\
\end{array}$ & $\begin{array}{l}\text { Diagnosed and } \\
\text { obstructive spirometry } \\
\text { RRR }(95 \% \mathrm{Cl}) \S \\
\end{array}$ \\
\hline \multicolumn{8}{|l|}{ Sex } \\
\hline Femalesף & 4372 & 1.00 & 1.00 & 1.00 & 1.00 & 1.00 & 1.00 \\
\hline Males & 3231 & 0.49 (0.31 to 0.79$)$ & 1.31 (1.16 to 1.49$)$ & $2.23(1.34$ to 3.71$)$ & $0.52(0.34$ to 0.81$)$ & $1.05(0.90$ to 1.23$)$ & $2.15(1.25$ to 3.71$)$ \\
\hline $\mathrm{p}$ Value & & 0.003 & $<0.001$ & 0.002 & 0.004 & 0.543 & 0.006 \\
\hline \multicolumn{8}{|l|}{ Age-group } \\
\hline $40-54 \prod$ & 3416 & 1.00 & 1.00 & 1.00 & 1.00 & 1.00 & 1.00 \\
\hline $55-64$ & 2022 & 1.26 (0.76 to 2.09$)$ & 2.08 (1.76 to 2.46$)$ & 4.06 (2.11 to 7.79$)$ & 1.34 (0.83 to 2.16$)$ & 1.09 (0.90 to 1.33$)$ & 2.91 (1.49 to 5.68 ) \\
\hline $65-74$ & 1451 & 1.47 (0.84 to 2.55$)$ & 3.05 (2.56 to 3.63$)$ & 4.78 (2.38 to 9.57$)$ & $1.27(0.74$ to 2.15$)$ & $1.02(0.82$ to 1.27$)$ & 3.12 (1.53 to 6.36$)$ \\
\hline $75+$ & 714 & 1.95 (0.69 to 5.51$)$ & 5.89 (4.76 to 7.29$)$ & 7.55 (3.35 to 17.02$)$ & 1.60 (0.67 to 3.81$)$ & 1.42 (1.08 to 1.87$)$ & 3.47 (1.43 to 8.40$)$ \\
\hline$p$ Value & & 0.388 & $<0.001$ & $<0.001$ & 0.535 & 0.085 & $<0.001$ \\
\hline \multicolumn{8}{|l|}{ Pack-years** } \\
\hline $0-0.9$ - & 4165 & 1.00 & 1.00 & 1.00 & 1.00 & 1.00 & 1.00 \\
\hline $1-19.9$ & 1835 & 1.08 (0.61 to 1.92$)$ & 1.67 (1.42 to 1.96$)$ & 2.84 (1.30 to 6.23$)$ & 1.16 (0.68 to 2.00$)$ & 2.02 (1.63 to 2.50$)$ & 2.58 (1.10 to 6.01$)$ \\
\hline $20-49.9$ & 1269 & 3.05 (1.68 to 5.54$)$ & 3.18 (2.70 to 3.74$)$ & 6.70 (3.35 to 13.40$)$ & 2.98 (1.72 to 5.16$)$ & 4.23 (3.44 to 5.20$)$ & $5.74(2.70$ to 12.20$)$ \\
\hline $50+$ & 334 & 3.94 (1.70 to 9.13$)$ & 4.15 (3.13 to 5.49$)$ & 18.50 (8.41 to 40.70$)$ & 3.87 (1.81 to 8.29$)$ & 6.83 (4.98 to 9.37 ) & 17.23 (7.37 to 40.28$)$ \\
\hline$p$ Value & & $<0.001$ & $<0.001$ & $<0.001$ & $<0.001$ & $<0.001$ & $<0.001$ \\
\hline \multicolumn{8}{|l|}{ NS-SEC ${ }^{* *}$} \\
\hline Professionalף & 3047 & 1.00 & 1.00 & 1.00 & 1.00 & 1.00 & 1.00 \\
\hline Intermediate & 1855 & $0.76(0.45$ to 1.30$)$ & $1.20(1.02$ to 1.41$)$ & 1.84 (0.87 to 3.87$)$ & $0.83(0.50$ to 1.40$)$ & 1.19 (0.97 to 1.47$)$ & $1.57(0.72$ to 3.44$)$ \\
\hline Routine & 2701 & 0.93 (0.59 to 1.48$)$ & 1.31 (1.12 to 1.53$)$ & 3.65 (1.89 to 7.06$)$ & $1.08(0.70$ to 1.67$)$ & 1.54 (1.27 to 1.87$)$ & 3.37 (1.70 to 6.68$)$ \\
\hline$p$ Value & & 0.612 & 0.002 & $<0.001$ & 0.632 & $<0.001$ & $<0.001$ \\
\hline \multicolumn{8}{|l|}{ Sample } \\
\hline UKHLSף & 5675 & 1.00 & 1.00 & 1.00 & 1.00 & 1.00 & 1.00 \\
\hline HSE & 1928 & 2.38 (1.54 to 3.69$)$ & 0.94 (0.81 to 1.09$)$ & $1.92(1.21$ to 3.05$)$ & 2.21 (1.46 to 3.35$)$ & $0.96(0.79$ to 1.16$)$ & 2.13 (1.31 to 3.48$)$ \\
\hline$p$ Value & & $<0.001$ & 0.420 & 0.006 & $<0.001$ & 0.664 & 0.002 \\
\hline
\end{tabular}

${ }^{*}$ Participants were included under each relevant definition. Bronchodilators were not used. Cell counts unweighted; RRRs estimated using survey weights.

TFTs: obstruction (FT): FEV /FVC <0.7. Diagnosed COPD: HSE: reported diagnosed chronic bronchitis, emphysema, or COPD; UKHLS: diagnosed bronchitis or emphysema.

fLLN: obstruction (LLN): FEV $/$ /FVC<LLN. Diagnosed COPD: HSE: reported diagnosed chronic bronchitis, emphysema, or COPD; UKHLS: diagnosed bronchitis or emphysema.

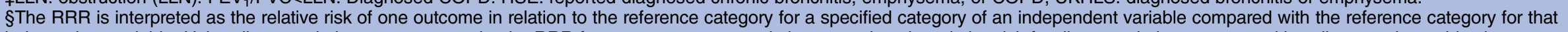

independent variable. Using diagnosed alone as an example, the RRR for men versus women is interpreted as the relative risk for diagnosed alone versus neither diagnosed nor objective

spirometry for men compared with the analogous relative risk for women, adjusted for the other variables in the model.

IReference category.

${ }^{\star *}$ Missing data: $12 / 7879(0.2 \%)$ pack-years of cigarette smoking; $265 / 7879(3.4 \%)$ NS-SEC

COPD, chronic obstructive pulmonary disease; FEV 1 , maximum expiratory volume in $1 \mathrm{~s}$; FTs, fixed thresholds; FVC, forced vital capacity; HSE, Health Survey for England; LLN, lower limit of

normal (below the 5th centile of Z-scores); NS-SEC, National Statistics Socio-Economic Classification; RRR; relative risk ratios; UKHLS, UK Household Longitudinal Survey. 
obstructed airflow, after adjustment for potential confounders, were sensitive to spirometric criteria, being higher among men for FT, compared with no difference using LLN.

\section{Strengths and limitations}

Analyses were based on nationally representative samples, with identical measurement protocols and specialist equipment for collecting lung function data. Combining the HSE and UKHLS data sets increased statistical precision for spirometry-based estimates, particularly for population subgroups, and allowed detailed analyses to be conducted. Predicted values and z-scores were obtained from the ERS GLI 2012 reference equations, ${ }^{28}$ facilitating inclusion of older participants, nonwhite populations and comparability with international studies. Our study has a number of limitations. Reversibility in airflow obstruction could not be assessed due to bronchodilators not being used. Spirometrybased prevalence, therefore, may be overestimated. Analysis of the National Health and Nutrition Examination Survey (NHANES) 2007-2010 showed that FT and LLN prevalence estimates among US adults aged 40-79 years decreased, in relative terms, by approximately one-third after administration of bronchodilators. ${ }^{45}$ Although recent guidelines from $\mathrm{NICE}^{46}$ and ERS $^{13}$ recommend use of postbronchodilator spirometry to confirm the presence of airflow obstruction, debate continues over its use in epidemiological settings, with the arguments against including ethical issues such as possible side effects and contraindications. ${ }^{47}$ Potential misclassification of disease status through bronchodilators not being used was reduced by excluding participants with physician-diagnosed asthma. Some participants in the analytical sample, however, may be undiagnosed asthmatics. On the other hand, the disease burden may be underestimated through excluding participants with poor-quality spirometry. Participation in spirometry, and achievement of good-quality standards among participants with any spirometry data, was higher among participants of younger age, engaged in professional/managerial occupations, non-smokers and with no physician-diagnosed COPD. Lower survey participation rates among sociodemographic groups at higher risk of airflow obstruction (eg, older persons, lower socioeconomic groups) would also have led to an underestimation of true prevalence. These limitations, however, are unlikely to affect comparisons across definitions, but may have led to an underestimate of risk associations. The list of health conditions in the UKHLS interview programme included chronic bronchitis and emphysema but not COPD, leading to potential underestimation of self-reported physician-diagnosed COPD.

\section{Comparisons with previous studies}

Earlier analyses of HSE data ${ }^{36}{ }^{38}$ used older reference equations ${ }^{49} 50$ applicable only to white, younger populations. Nevertheless, estimates of prevalence and their substantive conclusions of higher prevalence using FT versus LLN, with a widening gap in prevalence in older age groups, and sex differences when using FT but not LLN were similar to ours: confirming findings reported in the USA,${ }^{45}$ Europe,${ }^{51}$ Korea,${ }^{16}$ internationally, ${ }^{12}$ and in recent literature reviews. ${ }^{62}$ A further strength of our study was the wide range of clinically relevant conditions examined in the context of disease staging, with higher prevalence of respiratory symptoms, respiratory and cardiovascular diseases, breathlessness and poor self-rated health among participants in the tightest definitions of FT and LLN obstruction, confirming similar findings in the USA. ${ }^{53}{ }^{54}$ While recent guidelines ${ }^{13} 46 \quad 55$ recommend adopting multidimensional definitions of respiratory disease, our study outcomes were defined only using spirometry. While we acknowledge the merits of a multidimensional approach, and agree that neither spirometric cut-off is able to fully characterise the complex diagnostic features of COPD ${ }^{56}$ our primary aim was to use up-to-date survey data to evaluate differences in prevalence according to FT and LLN thresholds, to provide baseline data for monitoring purposes in the UK, and promote comparability with international studies. Current recommendations regarding symptom criteria are less specific than those for spirometry. We chose, therefore, to examine the associations between disease staging assessed only using spirometry and presence of respiratory symptoms, rather than broaden the definition of disease.

\section{Implications}

Recent UK studies used administrative primary care databases to report the number of diagnosed and treated patients, thereby missing undiagnosed cases. Such studies have reported prevalence below $2 \% .^{57} 58$ The disparity in prevalence from clinical versus epidemiological studies led to the development of the COPD prevalence model, with the HSE 2001 used as input data, to more accurately estimate prevalence. ${ }^{59} \mathrm{In}$ accordance with previous NICE recommendations, ${ }^{44}$ COPD is currently defined in the model as FT stage II+ $\left(\mathrm{FEV}_{1} / \mathrm{FVC}<0.7\right.$ and $\mathrm{FEV}_{1}<80 \%$ of predicted), with the logistic regression models showing sharp increases with age and a modifying effect of gender. ${ }^{60}{ }^{61}$ Similar to the findings reported by Jordan et al, ${ }^{36}$ our study shows that the strength of association between risk factors and airflow obstruction varies according to spirometric criterion, with age and sex differences in risk being more marked for FT, and for FT stage II+, than LLN. In the absence of agreement among experts, policymakers, clinicians and researchers building the COPD epidemiological database, it is important to appreciate the sensitivity of estimates of the disease burden, and its distribution across sociodemographic groups, to differences in methods, including spirometric cut-offs.

The prevalence of reported physician-diagnosed COPD in our study was $2.8 \%$, considerably lower than spirometry-based estimates, possibly indicating 
considerable under-recognition by participants and physicians. Using the tightest definitions, prevalence of physician-diagnosed COPD among participants with obstructive spirometry was $30.2 \%$ (FT stage III+) and $14.7 \%$ (LLN stage II). Similar low rates of physician diagnosis among participants meeting spirometric criteria have been reported in New Zealand. ${ }^{62}$ Spirometrically defined airflow obstruction but no diagnosed COPD does not necessarily indicate underdiagnosis. Definitive diagnosis requires further information on all relevant clinical factors, particularly respiratory symptoms and smoking history, as well as postbronchodilator spirometry.

\section{CONCLUSION}

In summary, we have enhanced the COPD epidemiological database by evaluating the impact of different definitions on the prevalence of potential airflow obstruction and its associations with key risk factors and comorbidities. With no gold standard currently available, longitudinal studies examining differences in unscheduled hospital admissions and risk of death between FT and LLN may inform the choice as to the best way to include spirometric data in multidimensional assessments of airflow obstruction in clinical and epidemiological settings.

Acknowledgements The authors thank Deborah Jarvis, Janet Stocks and Jessica Sheringham for helpful comments.

Contributors SS, AM and JSM participated in study concept and design, analysis and interpretation of data. SS performed data acquisition and management. SS participated in drafting of the manuscript. AM and JM aided revision of the manuscript and provided relevant intellectual input. SS is the data guarantor. All authors have approved the final version of the manuscript.

Funding The Health Survey for England 2010 was funded by the Health and Social Care Information Centre (HSCIC).

Competing interests None.

Ethics approval Ethical approval for collecting biosocial data in UKHLS was obtained from the Oxfordshire A Research Ethics Committee (10/H0604/2); approval for HSE 2010 was obtained from the Oxfordshire B Research Ethics Committee (09/H0605/73).

Provenance and peer review Not commissioned; externally peer reviewed.

Data sharing statement Both datasets are available via the UK Data Service (http://www.ukdataservice.ac.uk). Statistical code is available from the corresponding author at s.scholes@ucl.ac.uk.

Open Access This is an Open Access article distributed in accordance with the Creative Commons Attribution Non Commercial (CC BY-NC 4.0) license, which permits others to distribute, remix, adapt, build upon this work noncommercially, and license their derivative works on different terms, provided the original work is properly cited and the use is non-commercial. See: http:// creativecommons.org/licenses/by-nc/4.0/

\section{REFERENCES}

1. Mannino DM, Buist AS. Global burden of COPD: risk factors, prevalence, and future trends. Lancet 2007;370:765-73.

2. Raherison C, Girodet PO. Epidemiology of COPD. Eur Respir Rev 2009;18:213-21.

3. Lozano R, Naghavi M, Foreman K, et al. Global and regional mortality from 235 causes of death for 20 age groups in 1990 and
2010: a systematic analysis for the Global Burden of Disease Study 2010. Lancet 2012;380:2095-128.

4. Department of Health. An Outcomes Strategy for COPD and asthma: NHS Companion Document. 2012. https://www.gov.uk/ government/uploads/system/uploads/attachment_data/file/216139/ dh_128428.pdf

5. Atsou K, Chouaid C, Hejblum G. Variability of the chronic obstructive pulmonary disease key epidemiological data in Europe: systematic review. BMC Med 2011;9:7.

6. Rycroft CE, Heyes A, Lanza L, et al. Epidemiology of chronic obstructive pulmonary disease: a literature review. Int J Chron Obstruct Pulmon Dis 2012;7:457-94.

7. McLean S, Wild SH, Simpson CR, et al. Models for estimating projections for the prevalence and disease burden of chronic obstructive pulmonary disease (COPD): systematic review protocol. Prim Care Respir J 2013;22:S8-21.

8. Salvi SS, Manap R, Beasley R. Understanding the true burden of COPD: the epidemiological challenges. Prim Care Respir $J$ 2012;21:249-51.

9. Pauwels RA, Buist AS, Calverley PM, et al. Global strategy for the diagnosis, management, and prevention of chronic obstructive pulmonary disease. NHLBI/WHO Global Initiative for Chronic Obstructive Lung Disease (GOLD) Workshop summary. Am J Respir Crit Care Med 2001;163:1256-76.

10. Miller MR, Hankinson J, Brusasco V, et al. Standardisation of spirometry. Eur Respir J 2005;26:319-38.

11. Miller MR, Quanjer PH, Swanney MP, et al. Interpreting lung function data using $80 \%$ predicted and fixed thresholds misclassifies more than $20 \%$ of patients. Chest 2011;139:52-9.

12. Swanney MP, Ruppel G, Enright PL, et al. Using the lower limit of normal for the FEV1/FVC ratio reduces the misclassification of airway obstruction. Thorax 2008;63:1046-51.

13. Bakke PS, Ronmark E, Eagan T, et al. Recommendations for epidemiological studies on COPD. Eur Respir J 2011;38:1261-77.

14. Hansen JE, Sun XG, Wasserman K. Spirometric criteria for airway obstruction: use percentage of FEV1/FVC ratio below the fifth percentile, not $<70 \%$. Chest 2007;131:349-55.

15. Roberts SD, Farber MO, Knox KS, et al. FEV1/FVC ratio of $70 \%$ misclassifies patients with obstruction at the extremes of age. Chest 2006;130:200-6.

16. Hwang $\mathrm{YI}$, Kim CH, Kang HR, et al. Comparison of the prevalence of chronic obstructive pulmonary disease diagnosed by lower limit of normal and fixed ratio criteria. J Korean Med Sci 2009;24:621-6.

17. Quanjer PH, Cole TJ. COPD and GOLD stage I. Chest 2012;141:1122.

18. Enright P, Brusasco V. Counterpoint: should we abandon FEV(1)/ FVC $<0.70$ to detect airway obstruction? Yes. Chest 2010;138:1040-2.

19. Quanjer PH, Enright PL, Miller MR, et al. The need to change the method for defining mild airway obstruction. Eur Respir $J$ 2011;37:720-2.

20. Celli BR, Halbert RJ. Point: should we abandon FEV(1)/FVC $<0.70$ to detect airway obstruction? No. Chest 2010;138:1037-40.

21. Falaschetti E, Swanney MP, Crapo RO, et al. Diagnosis of COPD. Thorax 2007:62:924-5.

22. Halbert RJ, Natoli JL, Gano A, et al. Global burden of COPD systematic review and meta-analysis. Eur Respir J 2006;28:523-32.

23. Mindell J, Biddulph JP, Hirani V, et al. Cohort profile: the health survey for England. Int J Epidemiol 2012;41:1585-93.

24. Joint Health Surveys Unit. The Health Survey for England 2010, Volume 1: Respiratory Health. In: Craig R, Mindell J. eds. Respiratory health. Leeds: NHS Information Centre, 2011. http:// www.hscic.gov.uk/pubs/hse10report

25. Joint Health Surveys Unit. The Health Survey for England 2010, Volume 2: Methods and Documentation. Leeds: The Information Centre for Health and Social Care, 2011. http://www.hscic.gov.uk/ catalogue/PUB03023/heal-surv-eng-2010-resp-heal-vol2-methrep.pdf

26. Lynn P. Sample design for Understanding Society. Understanding Society Working Paper Series: 2009-01. https://www. understandingsociety.ac.uk/research/publications/working-paper/ understanding-society/2009-01.pdf

27. McFall SL, Petersen J, Kaminska O, et al. Understanding SocietyThe UK Household Longitudinal Study: Waves 2 and 3 Nurse Health Assessment, 2010-2012 Guide to Nurse Health Assessment. Colchester: University of Essex, 2012. https://www. understandingsociety.ac.uk/d/100/7251_User_Guide_Health Assmt_w2_w3.pdf?1392855567

28. Quanjer $\mathrm{PH}$, Stanojevic S, Cole TJ, et al. Multi-ethnic reference values for spirometry for the 3-95-yr age range: the global lung function 2012 equations. Eur Respir J 2012;40:1324-43. 
29. Quanjer PH, Brazzale DJ, Boros PW, et al. Implications of adopting the Global Lungs Initiative 2012 all-age reference equations for spirometry. Eur Respir J 2013;42:1046-54.

30. Hall GL, Thompson BR, Stanojevic S, et al. The Global Lung Initiative 2012 reference values reflect contemporary Australasian spirometry. Respirology 2012;17:1150-1.

31. Rabe KF, Hurd S, Anzueto A, et al. Global strategy for the diagnosis, management, and prevention of chronic obstructive pulmonary disease: GOLD executive summary. Am J Respir Crit Care Med 2007;176:532-55

32. COPD Guidelines Group of the Standards of Care Committee of the BTS. BTS guidelines for the management of chronic obstructive pulmonary disease. The COPD Guidelines Group of the Standards of Care Committee of the BTS. Thorax 1997;52 5):S1-28.

33. Ferguson GT, Enright PL, Buist AS, et al. Office spirometry for lung health assessment in adults: a consensus statement from the National Lung Health Education Program. Chest 2000;117:1146-61.

34. Vaz Fragoso CA, Concato J, McAvay G, et al. The ratio of FEV1 to FVC as a basis for establishing chronic obstructive pulmonary disease. Am J Respir Crit Care Med 2010;181:446-51.

35. Centers for Disease Control and Prevention (CDC). Deaths from chronic obstructive pulmonary disease-United States, 2000-2005. MMWR Morb Mortal Wkly Rep 2008;57:1229-32.

36. Jordan RE, Miller MR, Lam KB, et al. Sex, susceptibility to smoking and chronic obstructive pulmonary disease: the effect of different diagnostic criteria. Analysis of the Health Survey for England. Thorax 2012;67:600-5.

37. Bhatt SP, Sieren JC, Dransfield MT, et al. Comparison of spirometric thresholds in diagnosing smoking-related airflow obstruction. Thorax 2014;69:409-14.

38. Jordan RE, Cheng KK, Miller MR, et al. Passive smoking and chronic obstructive pulmonary disease: cross-sectional analysis of data from the Health Survey for England. BMJ Open 2011;1: e000153.

39. Woodward M. Epidemiology study design and data analysis. 2nd edn. Boca Raton, FL: Chapman \& Hall/CRC, 2004

40. Loong TW. Understanding sensitivity and specificity with the right side of the brain. BMJ 2003;327:716-9.

41. Rabe-Hesketh S, Skrondal A. Multilevel and longitudinal modeling using Stata: volume II: categorical responses, counts, and survival. 3rd edn. Stata Press, 2012.

42. UCLA Statistical Consulting Group. Multinomial Logistic Regression. http://www.ats.ucla.edu/stat/stata/dae/mlogit.htm

43. Hill K, Goldstein RS, Guyatt GH, et al. Prevalence and underdiagnosis of chronic obstructive pulmonary disease among patients at risk in primary care. CMAJ 2010;182:673-8.

44. Chronic obstructive pulmonary disease. National clinical guideline on management of chronic obstructive pulmonary disease in adults in primary and secondary care. Thorax 2004;59(Suppl 1):1-232.

45. Tilert T, Dillon C, Paulose-Ram R, et al. Estimating the U.S. prevalence of chronic obstructive pulmonary disease using pre- and post-bronchodilator spirometry: the National Health and Nutrition Examination Survey (NHANES) 2007-2010. Respir Res 2013;14:103.

46. National Institute for Health and Care Excellence (NICE). Chronic obstructive pulmonary disease: management of chronic obstructive pulmonary disease in adults in primary and secondary care. 2010. http://www.nice.org.uk/Guidance/CG101.

47. Quanjer PH, Stanojevic S, Swanney MP, et al. Recommendations for epidemiological studies on COPD. Eur Respir J 2012;39:1277-8.

48. Shahab L, Jarvis MJ, Britton J, et al. Prevalence, diagnosis and relation to tobacco dependence of chronic obstructive pulmonary disease in a nationally representative population sample. Thorax 2006;61:1043-7.

49. Quanjer PH, Tammeling GJ, Cotes JE, et al. Lung volumes and forced ventilatory flows. Report Working Party Standardization of Lung Function Tests, European Community for Steel and Coal. Official Statement of the European Respiratory Society. Eur Respir $J$ Suppl 1993;16:5-40.

50. Falaschetti $\mathrm{E}$, Laiho J, Primatesta $P$, et al. Prediction equations for normal and low lung function from the Health Survey for England. Eur Respir J 2004;23:456-63.

51. Maio S, Sherrill DL, MacNee W, et al. The European Respiratory Society spirometry tent: a unique form of screening for airway obstruction. Eur Respir J 2012;39:1458-67.

52. Mohamed Hoesein FA, Zanen $P$, Lammers JW. Lower limit of normal or FEV1/FVC <0.70 in diagnosing COPD: an evidence-based review. Respir Med 2011;105:907-15.

53. Mannino DM, Thorn D, Swensen A, et al. Prevalence and outcomes of diabetes, hypertension and cardiovascular disease in COPD. Eur Respir J 2008;32:962-9.

54. Ford ES, Wheaton AG, Mannino DM, et al. Elevated cardiovascular risk among adults with obstructive and restrictive airway functioning in the United States: a cross-sectional study of the National Health and Nutrition Examination Survey from 2007-2010. Respir Res 2012;13:115.

55. Vestbo J, Hurd SS, Agusti AG, et al. Global strategy for the diagnosis, management, and prevention of chronic obstructive pulmonary disease: GOLD executive summary. Am J Respir Crit Care Med 2013;187:347-65.

56. Clini EM, Crisafulli E, Roca M, et al. Diagnosis of chronic obstructive pulmonary disease, simpler is better. Complexity and simplicity. Eur J Intern Med 2013;24:195-8.

57. Haughney J, Gruffydd-Jones K, Roberts J, et al. The distribution of COPD in UK general practice using the new GOLD classification. Eur Respir J 2014;43:993-1002.

58. Simpson CR, Hippisley-Cox J, Sheikh A. Trends in the epidemiology of chronic obstructive pulmonary disease in England: a national study of 51804 patients. Br J Gen Pract 2010;60:277-84.

59. Walford H, Ramsey L. COPD Prevalence Modelling Briefing Document. 2011. http://www.apho.org.uk/resource/view.aspx? $\mathrm{RID}=111137$

60. Nacul LC, Soljak M, Meade T. Model for estimating the population prevalence of chronic obstructive pulmonary disease: cross sectional data from the Health Survey for England. Popul Health Metr 2007;5:8.

61. Nacul L, Soljak M, Samarasundera E, et al. COPD in England: a comparison of expected, model-based prevalence and observed prevalence from general practice data. J Public Health (Oxf) 2011;33:108-16.

62. Shirtcliffe $P$, Weatherall M, Marsh $S$, et al. COPD prevalence in a random population survey: a matter of definition. Eur Respir $J$ 2007;30:232-9. 